\title{
ELIMINABILITY OF “OPEN TEXTURE" OF LAW: THREE OBSERVATIONS OF R. DWORKIN ${ }^{1}$
}

\author{
Sergey N. Kasatkin \\ Samara Law Institute of the Federal Penitentiary Service of Russia, Samara, Russian Federation
}

\begin{abstract}
Introduction: the article addresses one of the aspects of the landmark dispute between the American jurist Ronald Dworkin (1931-2013) and his British colleague Herbert Hart (1907-1992) related to the problems of legal uncertainty and deficiency of law. If Hart declares the linguistically conditioned and irrevocable "openness" of law in borderline cases, R. Dvorkin emphasizes the existence of the only correct answer to any legal question, pointing to the mechanisms of circumventing the language uncertainty and ensuring the completeness of law. These include the canons of statutory interpretation, the duty of the judge to choose the most legitimate interpretation, as well as the rules of interpretation of the law by its undeniable linguistic significance. The purpose of the article is to study the ability of R. Dworkin's arguments to neutralize H. Hart's ideas on the basis of the general scientific and specific scientific methods. As a result, the article fixes $\mathrm{H}$. Hart's point of view on the "open texture" of law and various lines of counter argumentation on the part of R. Dworkin, summarizes and evaluates Dworkin's objections to the nonremovability of the problems of "open texture" in law. The article substantiates the conclusion about the insufficiency of R. Dworkin's arguments against the Hart's doctrine: the considered canons and rules of interpretation can reduce legal uncertainty, but not eliminate it in a fundamental way (generating multiplicity in the grounds of the truth of legal statements). More preferable for R. Dvorkin is the defense of the "thesis of the correct answer" through its connection with the institutional conventions of the legal system and challenging the possibility of its "external" criticism.
\end{abstract}

Key words: R. Dworkin, H. Hart, legal uncertainty, “open texture" of law, legal insufficiency, judicial discretion, thesis of the correct answer, interpretation of law.

Citation. Kasatkin S.N. Eliminability of "Open Texture" of Law: Three Observations of R. Dworkin. Legal Concept, 2019, vol. 18, no. 1, pp. 93-98. (in Russian). DOI: https://doi.org/10.15688/lc.jvolsu.2019.1.12

УДК $340.132 ; 340.12$

Дата поступления статьи: 20.01.2019

ББК $67.0 ; 67.1$

Дата принятия статьи: 15.02.2019

\section{УСТРАНИМОСТЬ «ОТКРЫТОЙ ТЕКСТУРЫ» ПРАВА: ТРИ ЗАМЕЧАНИЯ Р. ДВОРКИНА ${ }^{1}$}

\author{
Сергей Николаевич Касаткин \\ Самарский юридический институт ФСИН России, г. Самара, Российская Федерация
}

Введение: статья обращается к одному из аспектов знакового для западной юриспруденции спора между американским правоведом Рональдом Дворкиным (1931-2013) и его британским коллегой Гербертом Хартом (1907-1992), связанного с проблематикой правовой неопределенности и пробельности права.

Если Г. Харт заявляет о лингвистически обусловленной и неустранимой «открытости» права в пограничных

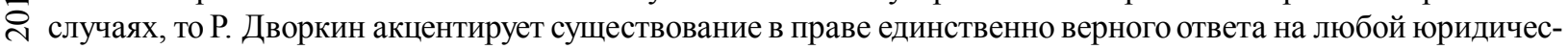
кий вопрос, указывая на механизмы обхода языковой неопределенности и обеспечения полноты права. Ч К таковым он относит каноны статутной интерпретации, обязанность судьи по выбору наиболее легитимного толкования, а также правила толкования закона по его неоспоримому языковому значению. Цель: на базе общенаучных и частнонаучных методов исследовать способность аргументов Р. Дворкина нейтрализовать идеи Г. Харта. Как результат в статье фиксируется позиция Г. Харта об «открытой текстуре» права и различ(2) ные линии контраргументации со стороны Р. Дворкина, обобщаются и оцениваются возражения Дворкина 


\section{ТЕОРИЯ И ПРАКТИКА ГОСУДАРСТВЕННО-ПРАВОВОГО РАЗВИТИЯ}

против неустранимости проблем «открытой текстуры» в праве. В статье обосновывается вывод о недостаточности аргументов Р. Дворкина против доктрины Г. Харта: рассматриваемые каноны и правила интерпретации способны уменьшить правовую неопределенность, но не устранить ее фундаментальным образом (порождая множественность в основаниях истинности правовых утверждений). Более предпочтительным для Р. Дворкина видится защита «тезиса правильного ответа» через его связь с институциональными конвенциями правовой системы и оспаривание возможности его «внешней» критики.

Ключевые слова: Р. Дворкин, Г. Харт, правовая неопределенность, «открытая текстура» права, правовой пробел, судейское усмотрение, тезис правильного ответа, толкование права.

Цитирование. Касаткин С. Н. Устранимость «открытой текстуры» права: три замечания Р. Дворкина // Legal Concept = Правовая парадигма. -2019 . - T. 18, № 1. - C. 93-98. - DOI: https://doi.org/10.15688/ lc.jvolsu.2019.1.12

\section{Введение}

Настоящая статья обращается к значимой для англо-американской правовой мысли полемике Рональда Дворкина с юридическим позитивизмом и сосредоточивается на анализе контраргументов американского мыслителя против идеи неустранимости «открытой текстуры» права, предложенной британским коллегой Дворкина - Гербертом Хартом и широко используемой позитивистскими и непозитивистскими доктринами. Г. Харт подчеркивает фундаментальную открытость языковых терминов в их применении к пограничным случаям, что порождает недоопределенность юридических правил и потребность в судейском усмотрении. В противовес этому Р. Дворкин отстаивает тезис о существовании в праве единственно верного ответа даже в сложных делах: так, в работе «Нет правильного ответа?» [7] он стремится показать механизмы преодоления проблем «открытой текстуры» права и обеспечения его полноты. Оценка состоятельности соответствующих доводов Дворкина и образует главную цель настоящего исследования.

\section{«Открытая текстура» права: Г. Харт}

В рамках своей общей, описательной и морально-нейтральной концепции права, синтезирующей идеи юридического позитивизма и философии языка [1], Г. Харт выдвигает тезисы умеренной неопределенности права и ограниченного судейского усмотрения. Отталкиваясь от социального (конвенционального) характера связи между термином / правилом и социальной ситуацией, философ указывает на существование и различение ясных (типич- ных) и неясных (периферийных) случаев употребления термина / правила, присущих им «ядра» и «полутени» значения. По Харту, языковым терминам и основанным на них юридическим правилам присуща «открытая текстура», то есть неопределенность применения в пограничных обстоятельствах. В такой ситуации принятие судебного решения не может предопределяться лишь имеющимися правовыми стандартами и требует выбора между альтернативами, то есть усмотрения $[2 ; 9$, p. 124-135, 272-276].

Харт иллюстрирует свой тезис на примере правила о запрете нахождения транспортного средства в парке: «Конкретные фактические ситуации не ожидают нас уже выделенными друг относительно друга и отмеченными в качестве примеров употребления общего правила, исследуемого на предмет его применения; не может и само такое правило выступить вперед, чтобы заявить о примерах своего собственного употребления. Во всех областях опыта... существует предел, свойственный природе языка, по отношению к тому руководству, которое может обеспечить язык общих терминов... Будут иметь место ясные случаи, постоянно повторяющиеся в схожих обстоятельствах, по отношению к которым четко применимы соответствующие общие выражения ("Если что-то и является транспортным средством, то это - автомобиль”), но наряду с этим будут существовать и случаи, когда непонятно, применяются ли к ним подобные выражения или нет ("Распространяется ли используемый здесь термин «транспортное средство» на велосипеды, самолеты, роликовые коньки?"). К последним относятся фактические ситуации, которые непрерывно подбрасывает природа или человеческое 
изобретение, имеющие лишь некоторые из признаков, свойственных ясным случаям, но также и иные признаки, которые у таковых отсутствуют... Ясный случай, когда общие термины, как кажется, не нуждаются в толковании и когда определение примеров их употребления видится беспроблемным или "автоматическим”, образуют только знакомые случаи, постоянно повторяющиеся в схожих обстоятельствах, по которым имеется общее согласие в суждениях относительно применимости классифицирующих терминов» [9, р. 126]. И далее: «Общие термины были бы... бесполезны в качестве средства общения, если бы не было таких знакомых, в целом не подвергающихся сомнению случаев. Но модификации знакомого тоже требуют классификации с помощью общих терминов, которые в любой рассматриваемый момент образуют часть наших языковых ресурсов. Здесь мы ввергаемся во что-то, похожее на кризис коммуникации: имеются доводы и “за”, и “против" использования нами общего термина, и никакой устойчивой конвенцией... не диктуется его употребление... Для того чтобы разрешить... [сомнения], нужно совершить нечто вроде выбора между открытыми альтернативами» [9, p. 126-127].

Осмысленная таким образом «открытая текстура», согласно Г. Харту, образует неустранимое свойство существующих языков, что обусловливает фундаментальную недоопределенность права и неизбежность судейского усмотрения: предварительная и исчерпывающая регламентация какой-либо сферы посредством общих языковых образцов невозможна в силу нашего ограниченного знания / предвидения будущих фактов и неопределенности осуществления наших целей в новых обстоятельствах [9, p. 128]. Вместе с тем судейское усмотрение, по мысли философа, имеет подчиненный статус в правовой системе и по частоте возникновения неурегулированных правом пограничных ситуаций, относительноредких на практике [9, p. 134 $135,154]$, и по опоре на устоявшиеся правила: судья вписывает нестандартный случай в сложившуюся систему словоупотребления и регламентации, исходя из его юридической уместности и содержательной близости имеющимся образцам (ясным референтам правовых норм и их телеологии) [9, p. 124-129].

\section{«Бесшовное сплетение» права и каноны интерпретации: Р. Дворкин}

В своей («ранней») критике предлагаемой Г. Хартом доктрины неопределенности и усмотрения Р. Дворкин использует различные варианты контраргументации [2].

Так, в очерке «Модель правил» он вводит идею правовых принципов как особых юридических предписаний, ключевых для судебного решения. Не будучи связанными с конкретными образцами действия, принципы формируют доводы в ту или иную пользу, исключают ситуации пробельности и, тем самым, усмотрения в праве, конституируя предзаданное существование юридических прав и обязанностей даже в спорных случаях [8, p. 14-45].

В очерке «Сложные дела» «тезис о принципах» провозглашается Р. Дворкиным как идеологическая и институциональная основа судебной деятельности: судьи выносят и должны выносить решения, исходя из защиты индивидуальных или коллективных прав (в противовес законодательной ориентации на политические цели). При этом судьи опираются на создаваемую ими наилучшую теорию рассматриваемого дела как совокупность принципов, наиболее соответствующих институциональной истории правовой системы (прежним решениям) и дающих ей наилучшее оправдание. Отсюда даже в спорных случаях судья не действует как законодатель, будучи связан легитимированными правовыми принципами и собственными институциональными обязанностями. Право выступает здесь не «открытой текстурой», а «бесшовным сплетением» [8, p. 81-130].

В очерках «Нет правильного ответа?» и «Могут ли права быть спорными?» Р. Дворкин выступает с тезисом «правильного ответа» как нормативно-конвенциональной основы института судопроизводства и права в целом, в рамках которых устанавливаются особые условия истинности правовых утверждений для любых, в том числе сложных, юридических дел [7; 8, p. 179-190].

С позиций доктрины «правильного ответа» Р. Дворкин оспаривает концепцию Г. Харта, выдвигая три аргумента против неустранимости «открытой текстуры», настаивая на том, что неопределенность с необходимостью 
не ведет к пробельности или неполноте права. Дворкин указывает на сформулированные судьями и юристами способы обхода проблем неопределенности как отдельных слов, используемых в законодательных текстах, так и закона в целом.

Во-первых, это каноны толкования законов, которые «определяют то, какую силу надлежит придать неясному слову в конкретном случае, или по крайней мере ставят ее силу в зависимость от дальнейших вопросов, которые в принципе имеют правильный ответ» [7, p. 68].

Во-вторых, это имеющиеся у судьи обязанности выбрать из числа разрешенных толкований неясного закона такую интерпретацию, которая «способствует наибольшему осуществлению совокупности принципов и целей, обеспечивающих наилучшее политическое оправдание закона на момент его принятия» [7, p. 68].

В-третьих, это возможность для юриста утверждать: в случае неопределенности закона следует полагать, что таковой изменяет предшествующее положение дел «только в той мере, в какой это оправдано неоспоримым ядром используемого языка» (например, как при толковании уголовных законов) [7, p. 68].

Разберем доводы Р. Дворкина более подробно, оценивая то, насколько они весомы в нейтрализации соответствующих взглядов Г. Харта:

1. Предлагаемый Р. Дворкиным аргумент о канонах интерпретации (причем в контексте, не сводимом лишь к толкованию законов) оправдан в том смысле, что Г. Харт практически не обращается к вопросам интерпретации, несмотря на важность последних. Очевидно, что каноны толкования опосредуют применение общих правил языка к праву, а потому способны нейтрализовать неопределенность, проистекающую из лингвистических фактов (на которых и строится учение Харта). Более того, правила интерпретации опосредуют применение любого правила, соучаствуя в конституировании их ясных, парадигмальных случаев, значимых для существования юридической регламентации в целом. Это, в свою очередь, указывает на системный характер права и нормативных оснований судебного решения, не сводимых к применению отдельных предписаний, тради- ционно анализируемых Хартом (по примеру правила «Нахождение транспортного средства в парке запрещено»), а также позволяет рассматривать каноны толкования в числе формулируемых британским мыслителем метаправил системы: правил признания, изменения и суда [3].

Вместе с тем довод Р. Дворкина находит прямое и весьма убедительное опровержение в тексте Г. Харта. Последний не только не отрицает значимости канонов толкования в обеспечении системности права и правоприменения, но и прямо признает их роль в уменьшении юридической неопределенности. Но, главное, Харт подчеркивает неспособность интерпретативных канонов принципиальным образом устранить «открытую текстуру» языка и права. Подобно Л. Витгенштейну, для которого правило не объясняется через бесконечный ряд интерпретаций, Харт заявляет: «Каноны “толкования” не способны устранить... случаи неопределенности [в праве], хотя они и могут их уменьшить. Ибо эти каноны сами являются общими правилами употребления языка и употребляют общие термины, которые сами требуют толкования. Точно так же, как и другие правила, они не могут обеспечить собственную интерпретацию» $[9$, p. 126].

2. Еще менее уместным видится аргумент Р. Дворкина, утверждающий обязанность судьи по выбору наиболее оправданного толкования закона. С одной стороны, данное правило, являясь примером канона интерпретации (если оно вообще признается в правовой системе), может вести к уменьшению проблем «открытой текстуры», но не устранить их полностью, поскольку оно также может потребовать разъяснений в отношении как его общего понимания, так и применения к конкретным случаям. В частности, сюда будет относиться определение того, что принимается за «разрешенное толкование» и, конечно, того, какое толкование дает наилучшую морально-политическую легитимацию прежних решений. Решение последней задачи усложняется тем, что для Дворкина принципы (a, вероятно, и политические цели) в отличие от правил не имеют четкого содержания и веса и определяются во взаимосвязанной и изменчивой системе стандартов и практик [8, р. 36], 
увеличивая поле возможных интерпретаций: вопреки американскому мыслителю [8, p. 286], чем большее число стандартов включает правопорядок, тем больше имеется конкурирующих вариантов их согласования и тем более абстрактным и туманным становится предлагаемый им критерий интерпретации (преодоления неопределенности).

3. Схожая оценка верна и в отношении третьего аргумента Р. Дворкина, который предписывает правило строгого толкования закона из его «неоспоримого» содержания. Как частный случай интерпретативного канона, оно также не обеспечивает полного устранения проблем «открытой текстуры». Само правило видится здесь проблемным в качестве критерия интерпретации: утверждать, что можно истолковать закон путем произвольного сведения сферы применения термина к ясным случаям его употребления, означает (необоснованно) предполагать, что можно провести четкую границу между ясными и неясными случаями применения термина, даже несмотря на то, что провести границу между тем, где данный термин применяется, а гденет, нельзя. Вдобавок рассматриваемое правило рождает новые сложные вопросы: например, сколько неопределенности и какого рода необходимо для того, чтобы показать начало пограничных случаев? Как быть, если все согласны в том, что термин применяется к конкретному случаю, но не согласны, что данный случай «ясный» или «простой»? В свете сказанного более предпочтительной представляется модель «континуума» или «спектра»: от простых случаев употребления термина / правила через полутень к ясным случаям их неприменения [4, p. 31-32; 10, p. 73-74]. Описанная невозможность четких разграничений «ядра» и «полутени», несомненно, присуща и рассуждениям Харта, обусловливая абстрактность его идеи «открытой текстуры», ее ограниченную практико-доктринальную ценность [2]. В отношении же Дворкина она показывает слабость его доводов для опровержения позиций оппонента.

\section{Выводы}

Таким образом, сами по себе рассмотренные аргументы Р. Дворкина видятся недо- статочными против тезисов Г. Харта об «открытой текстуре» языка и права. Каноны интерпретации, действительно, способны уменьшить правовую неопределенность, но не устранить ее фундаментальным образом (что потенциально влечет за собой сохранение множественности в основаниях истинности правовых утверждений, идущей вразрез с концепцией американского мыслителя). Отсюда представленные аргументы как доводы в пользу тезиса единственно верного ответа гораздо менее предпочтительны по сравнению с иной линией рассуждений Дворкина, связывающей существование такого ответа с институциональными конвенциями правовой системы и далее с попыткой нейтрализации ее «внешней» (в том числе позитивистской) критики [8, p. 179-190]. В последнем случае речь идет не только о необходимом включении правовой неопределенности в институциональные контексты современных / сложных правопорядков (что вполне допускается Хартом, утверждающим открытость права и наличие судейского усмотрения вне зависимости от официального признания [9, p. 129]), но и о проблематизации самой возможности оспаривания доктрины правильного ответа с внеинституциональной (квазиобъективной) точки зрения [5; 6, p. 45-113].

\section{ПРИМЕЧАНИЕ}

${ }^{1}$ Публикация подготовлена при финансовой поддержке Российского фонда фундаментальных исследований, проект № 18-011-01213 «Право как целостность - право как интерпретация: теоретико-методологическая и проблемно-историческая реконструкция доктрины юридического интерпретативизма Рональда Дворкина (1967-1986)».

\section{СПИСОК ЛИТЕРАТУРЫ}

1. Касаткин, С. Н. Анализ языка и объяснение правовых понятий: философско-лингвистическая методология Г. Харта / С. Н. Касаткин // Современные подходы к пониманию права и их влияние на развитие отраслевой юридической науки, законодательства и правоприменительной практики : сб. науч. тр. Минск : Академия МВД, 2017. -С. 99-109.

2. Касаткин, С. Н. Проблема судейского усмотрения в полемике Харта и Дворкина: линии ар- 
гументации и методологические истоки спора / С. Н. Касаткин // Правоведение. - 2012. - № 3. C. 11-34; № 4. - C. 10-33.

3. Aust, H. P. The Rules of Interpretation as Secondary Rules: The Perspective of Domestic Courts / H. P. Aust // The Rule of Law in Global Governance. London : Palgrave Macmillan, 2016. - P. 59-93.

4. Bix, B. Law, Language, and Legal Determinacy / B. Bix. - Oxford: Clarendon Press, 1993. - 221 p.

5. Dworkin, R. Hart's Postscript and the Character of Political Philosophy / R. Dworkin // Oxford Journal of Legal Studies. - 2004. - Vol. 24. - № 1. P. 1-37.

6. Dworkin, R. Law's Empire / R. Dworkin. Cambridge, Mass. : HUP, 1986. - 470, xiii p.

7. Dworkin, R. No Right Answer? / R. Dworkin // Law, Morality and Society. Essays in Honour of H.L.A. Hart. - Oxford : OUP, 1977. - P. 58-84.

8. Dworkin, R. Taking Rights Seriously / R. Dworkin. $-2^{\text {nd }}$ ed. - Cambridge, Mass. : HUP, 1978. $-392 \mathrm{p}$.

9. Hart, H. L. A. The Concept of Law / H. L. A. Hart. $-2^{\text {nd }}$ ed. - Oxford : Clarendon Press, 1994. $-336 \mathrm{p}$.

10. Raz, J. Authority of Law: Essays on Law and Morality/J. Raz. - Oxford: Clarendon Press, 1979.-289p.

\section{REFERENCES}

1. Kasatkin S.N. Analiz yazyka i obyasnenie pravovykh ponyatiy: filosofsko-lingvisticheskaya metodologiya G. Harta [Analysis of Language and Explanation of Legal Concepts: H. Hart's PhilosophicalLinguistic Methodology]. Sovremennyie podkhody k ponimaniyu prava i ikh vliyanie na razvitie otraslevoy yuridicheskoy nauki, zakonodatelstva $i$ pravoprimenitelnoy praktiki: sb. nauch. tr. [Contemporary Approaches to Understanding of Law and their Influence on Development of Branch Legal Sciences, Legislation and Law-Enforcement Practice: Collection of Scientific Works]. Minsk, Akademiya MVD, 2017, pp. 99-109.

2. Kasatkin S.N. Problema sudeyskogo usmotreniya v polemike Harta i Dvorkina: linii argumentatsii i metodologicheskie istoki spora [A problem of Judicial Discretion in Hart-Dworkin Polemic: Lines of Argumentation and Methodological Sources of the Debate]. Pravovedeniye, 2012, no. 3, pp. 11-34, no. 4, pp. 10-33.

3. Aust H.P. The Rules of Interpretation as Secondary Rules: The Perspective of Domestic Courts. The Rule of Law in Global Governance. London, Palgrave Macmillan, 2016, pp. 59-93.

4. Bix B. Law, Language, and Legal Determinacy. Oxford, Clarendon Press, 1993. 221 p.

5. Dworkin R. Hart's Postscript and the Character of Political Philosophy. Oxford Journal of Legal Studies, 2004, vol. 24, no. 1, pp. 1-37.

6. Dworkin R. Law's Empire. Cambridge, Mass., HUP, 1986. 470, xiii p.

7. Dworkin R. No Right Answer? Law, Morality and Society. Essays in Honour of H.L.A. Hart. Oxford, OUP, 1977, pp. 58-84.

8. Dworkin R. Taking Rights Seriously. $2^{\text {nd }}$ ed. Cambridge, Mass., HUP, 1978. 392 p.

9. Hart H.L.A. The Concept of Law. $2^{\text {nd }}$ ed. Oxford, Clarendon Press, 1994. 336 p.

10. Raz J. Authority of Law: Essays on Law and Morality. Oxford, Clarendon Press, 1979. 289 p.

\section{Information about the Author}

Sergey N. Kasatkin, Candidate of Sciences (Jurisprudence), Associate Professor, Professor, Department of the Theory and History of State and Law, Samara Law Institute of the Federal Penitentiary Service of Russia, Rylskaya St., 24V, 443022 Samara, Russian Federation, tigp@samlawin.ru, kasatka_s@bk.ru,https://orcid.org/0000-0001-5541-9181

\section{Информация об авторе}

Сергей Николаевич Касаткин, кандидат юридических наук, доцент, профессор кафедры теории и истории государства и права, Самарский юридический институт ФСИН России, ул. Рыльская, 24в, 443022 г. Самара, Российская Федерация, tigp@samlawin.ru, kasatka_s@bk.ru, https:/orcid.org/ 0000-0001-5541-9181 